\title{
BBEP
}

\section{Ensino de Ciências e de Matemática: resenhas e reflexões}

Marco Antonio Moreira

\section{Resumo}

Inicialmente é feita uma breve resenha de cada um dos 14 artigos subordinados à temática Ensino de Ciências e de Matemática publicados na Revista Brasileira de Estudos Pedagógicos (Rbep) no período 1998-2011. A seguir são feitos comentários e críticas sobre esse ensino no Brasil, assim como sobre a pesquisa nessa área, tendo como referência o já mencionado conjunto de artigos e a experiência do autor como professor e pesquisador em Ensino de Ciências, particularmente em Física.

Palavras-chave: Ensino de Ciências e de Matemática; pesquisa em Ensino de Ciências e de Matemática; análise crítica. 


\section{Abstract}

\section{Sciences and Mathematics Teaching: reviews and reflections}

Initially a short review is made of each one of a set of 14 articles published in the Brazilian Journal of Pedagogical Studies, from 1998 to 2011, in the area of Sciences and Mathematics teaching. Then, some comments and criticisms are made about this field of teaching in Brazil, as well as about the research done in it, taking as reference that set of articles and the author's experience as teacher and researcher in Sciences teaching, particularly in Physics.

Keywords: sciences and mathematics teaching; research in sciences and mathematics teaching; critical analysis.

\section{Apresentação}

O objetivo deste artigo é o de sintetizar e comentar o que foi publicado na Revista Brasileira de Estudos Pedagógicos (Rbep) na área de Ensino de Ciências e de Matemática, de 1998 (após o número comemorativo dos 60 anos) a 2011, integrando um número especial da Rbep para 2012, em comemoração aos 75 anos do Instituto Nacional de Estudos e Pesquisas Educacionais Anísio Teixeira (Inep).

Foram analisados 14 textos, dos quais oito focalizaram o Ensino da Matemática, três abordaram o Ensino de Física, dois, o Ensino de Ciências e um tratou do Ensino Inicial da Biologia. Dos oito que se ocuparam do Ensino de Matemática, sete enfocaram o ensino fundamental e um, o ensino médio. Assim, dos 14 artigos, nove são sobre Ciências e Matemática no ensino fundamental e cinco no ensino médio (três em Física, um em Matemática e um em Biologia).

Na seção seguinte serão apresentadas, em ordem cronológica, breves resenhas dos artigos em pauta. Nas demais seções, serão feitas observações gerais e comentários críticos sobre o ensino de Ciências e de Matemática no Brasil, no momento atual.

\section{Resenhas}

O trabalho de Nascimento (2000) registra que a geometria euclidiana tem sido menos trabalhada no Ensino de Matemática e argumenta que esse declínio não está na insatisfação com o conteúdo em si, mas com as dificuldades conceituais advindas das argumentações lógicas que constituem sua 
essência. Segundo esse autor, a maioria das dificuldades que se observam nos alunos na aprendizagem da geometria está relacionada com a maneira de organizarem o raciocínio e construírem argumentações lógicas; por isso, é preciso mudar o ensino da geometria, inserir nele a tecnologia do presente e mostrar como os conceitos e ideias dessa disciplina se aplicam em diversas áreas de conhecimento e no cotidiano dos seres humanos. Além disso, os alunos deveriam experimentar a geometria ativamente, e uma maneira de lhes proporcionar essa experiência é por meio da informática. A partir daí é apresentado o ambiente Logo como um meio de comunicação capaz de criar um ambiente construtivista, com vários exemplos.

Bellini (2007) utiliza a teoria de Piaget como referencial para pensar a epistemologia da Biologia e as diferenças epistemológicas em relação à Matemática e à Física, destacando implicações para a iniciação ao Ensino da Biologia. A autora inicialmente critica o Ensino de Ciências na escola, que é apenas verbal, impulsionado pelos livros didáticos usados como recursos expositivos, deixando em segundo plano aspectos fundamentais para a aprendizagem de Ciências, como a observação e a experimentação. Fundamentando muito bem a questão epistemológica, comparando a Biologia com a Física e a Matemática, argumenta que o pensamento biológico é, antes de tudo, realista, ou seja, não pode prescindir dos seres naturais, homens, animais e plantas. Na Matemática, recorre-se sobretudo às atividades dedutivas, não sendo necessária a observação e a experimentação, como na Física e na Biologia. Na Física, os conhecimentos construídos podem alcançar certo grau de generalidade que a experiência e a atividade do sujeito físico confundem com os esquemas matemáticos necessários a sua formalização. Portanto, o conhecimento biológico é mais realista que o conhecimento físico. Ante tais diferenças epistemológicas, a autora argumenta que não é possível ensinar essas disciplinas com o mesmo padrão metodológico. Sempre usando o referencial piagetiano, são apresentados exemplos e implicações para a iniciação à Biologia.

O lúdico no processo ensino-aprendizagem de Ciências é o tema do trabalho de Silva, Mettrau e Barreto (2007), partindo de uma perspectiva em que as concepções prévias de conceitos científicos sejam compreendidas como pontos de partida para a construção de conceitos científicos. Nessa perspectiva, que segundo os autores é coerente com a epistemologia genética de Piaget e o socioconstrutivismo de Vygotsky, o objeto de estudo é apreendido por meio de uma estrutura cognitiva constituída pelo sujeito a partir de seus interesses e necessidades. A motivação vem a ser, então, o elemento propulsor nesse processo, o que implica envolver o aluno em algo que tenha significado para si. Dessa maneira, o novo conhecimento é assimilado a uma rede anterior de significados que lhe dá sentido. Contudo, não é apenas o gostar que impulsiona a aprendizagem, mas a necessidade de se expressar no e para o mundo físico e social no qual se insere o sujeito. Com base em considerações dessa natureza, os autores propõem o jogo como estratégia de motivação e de levar em conta as ideias prévias dos alunos. Segundo eles, de nada adianta desenvolver em sala de 
aula um formalismo lógico-matemático de determinado problema se este não se constitui um problema para o aluno. É necessário que os alunos se sintam seduzidos pelo que lhes é apresentado e encontrem significação nas atividades desenvolvidas. O lúdico, em particular o jogo, pode ajudar bastante nesse processo, cujo objetivo é a aprendizagem de conceitos e procedimentos científicos.

A análise discursiva de um caderno de Ciências e a proposta de uma metodologia de análise que poderá ser aplicada a um volume maior de cadernos e revelar aspectos relevantes das práticas docentes e discentes no Ensino de Ciências são o objeto do artigo de Siqueira e Araújo-Jorge (2008). Segundo as autoras, os cadernos escolares trazem marcas da aprendizagem e exercício da escrita. Comum a todos os alunos, o caderno é um lugar onde se copiam lições e se registram conhecimentos retirados dos livros ou explicados pelo professor. Apoiadas em Vygotsky, Bakhtin e em algumas pesquisas, destacam a potencialidade dos cadernos escolares como registros para a investigação no Ensino de Ciências. Embora jamais retratem o que de fato aconteceu, os cadernos escolares documentam parte do ensinado e do aprendido. Como foi dito, é apresentado no artigo o caso da análise de um caderno escolar e proposta uma metodologia para a análise sistemática de cadernos que poderá ser útil para outros pesquisadores interessados em explorar o grande potencial desse tipo de registro na pesquisa qualitativa, interpretativa, no Ensino de Ciências.

A relação entre o domínio afetivo e o desempenho em Matemática de estudantes das séries iniciais do ensino fundamental foi o objeto de estudo de Cazorla, Utsumi, Santana e Vita (2008). Os autores criticam a abordagem tradicional ao Ensino de Matemática, no qual os professores insistem que os alunos façam muitas contas, muitos cálculos, resolvam muitos problemas e valorizam a repetição, a memorização e a mecanização, sem conexão com outras matérias do currículo escolar e sem dar importância à associação entre os domínios cognitivo e afetivo. A pesquisa feita focalizou justamente esse aspecto, ou seja, a relação entre esses domínios. Foi do tipo levantamento (survey), envolvendo 1.021 alunos de $1^{\mathrm{a}}$ a $4^{\mathrm{a}}$ série do ensino fundamental, de 26 escolas pertencentes a seis municípios do sul da Bahia. O instrumento foi um teste composto de 15 problemas de adição e subtração e um pequeno questionário com perguntas referentes a idade, sexo, sentimentos em relação à Matemática e à pessoa que auxiliava o sujeito nas tarefas matemáticas. A maioria dos estudantes (56,5\%) afirmou gostar muito da Matemática. Não foram encontradas diferenças quanto ao gênero no desempenho e gosto pela Matemática. Observou-se que os estudantes que afirmaram dar valor à Matemática e confiar em sua capacidade cognitiva obtiveram melhor desempenho na resolução dos problemas. Embora tenha ficado abaixo da expectativa, os autores argumentam que esse desempenho parece indicar que a crença de que os meninos gostam mais da Matemática e são mais competentes nessa disciplina não se sustenta e que é necessário buscar uma abordagem ao Ensino de Matemática que não seja transmissivo e centrado em exercícios memorísticos e não dissocie os domínios cognitivo e afetivo. 
O estudo de Diogo e Gobara (2008) apresenta uma retrospectiva do Ensino de Ciências, em particular do Ensino de Física, desde a instauração da primeira escola brasileira (1549) até o final da Era Vargas (1964). Segundo os autores, desde a criação dessa primeira escola (jesuítica) na Bahia até a chegada da família real portuguesa, em 1808, salvo raras iniciativas ou tentativas de introdução do Ensino de Ciências Naturais, o domínio do Ensino de Humanidades era quase absoluto. Os métodos pedagógicos nesse período eram a preleção, a competição, a memorização e os exercícios escritos. Mesmo com a criação do Colégio Pedro II e dos liceus, após a independência, pouca importância foi dada ao ensino científico. A disciplina de Física, por exemplo, não existia como disciplina isolada no Colégio Pedro II até 1925. E o Ensino das Ciências Naturais continuava puramente expositivo e baseado em manuais didáticos estrangeiros; além disso, tinha forte influência positivista. Na retrospectiva dos autores, a péssima situação em que se encontrava o Ensino de Física e de Ciências Naturais no início do período republicano perdurou até o início da década de 20 do século passado. Na Era Vargas (1930-1964), houve mudanças no sentido de universalizar a educação, atingindo um maior contingente da população. Foram criados cursos técnicos, e o ensino secundário foi dividido em dois ciclos, dos quais o segundo assumiu um caráter eminentemente propedêutico, para o ingresso em cursos superiores, com um currículo enciclopédico e um ensino expositivo, transmissivo. Mais tarde esses ciclos passaram a ser o ginasial (quatro anos) e o colegial (três anos), mas este continuou voltado primordialmente à preparação para o exame de admissão (vestibular) ao ensino superior. Referindo-se mais ao Ensino de Física, os autores destacam iniciativas importantes, como os projetos Physical Science Study Committee (PSSC), Física Auto-Instrutiva (FAI), Projeto de Ensino de Física (PEF) e a organização dos Simpósios Nacionais de Ensino de Física a partir de 1970. Contudo, na prática, o impacto dessas iniciativas foi pequeno, pois o Ensino de Física continua expositivo, baseado na memorização de fórmulas, com número insuficiente de aulas e excessivamente dependente de manuais didáticos.

Outro trabalho voltado diretamente à sala de aula é o de Berti, Rosso e Burak (2008), que investiga a compreensão e o significado que alunos de uma classe de $5^{\mathrm{a}}$ série têm sobre seus próprios erros e o ensino-aprendizagem da Matemática, tendo como referencial a teoria piagetiana do conhecimento lógico-matemático, da operatividade e da afetividade. Os autores criticam o ensino tradicional da Matemática, que cobra algoritmos, fórmulas, memorização, desempenho e aprovação sem garantia de compreensão dos conceitos e procedimentos. Defendem, então, o aproveitamento do erro, que pode ser superado, não apenas negado. O estudo buscou respostas para a seguinte pergunta: O que revelam os alunos sobre a natureza e a significância do conhecimento matemático e que contribuições o trabalho com seus erros pode trazer à prática pedagógica? A pesquisa foi do tipo qualitativa, em uma escola estadual paranaense, registrando a percepção de 36 alunos de $5^{\mathrm{a}}$ série sobre o processo de ensino-aprendizagem e os erros cometidos no seu 
decurso, através de questionário e observações livres anotadas em um diário. Os achados sugerem que a concepção do conhecimento lógico-matemático subjacente ao ensino é empirista, pautado pelo exercício, repetição de modelos, regras e técnicas sem compreensão crítica. A correção do erro se expressa na cópia da resolução correta exposta no quadro, sem tempo para qualquer discussão. Os alunos acreditam que se chega ao conhecimento matemático somente com muita disciplina, exercício e esforço, o que não estimula a participação e a satisfação. O erro não é aproveitado como variável na aprendizagem do conhecimento matemático; para o professor, ocupar-se do erro é perder tempo, em face do excessivo conteúdo programático. Os alunos, por sua vez, remetem aos professores parte da responsabilidade por seus erros e não apresentam disposição para aprender Matemática.

Magina, Bezerra e Spinillo (2009) relatam uma pesquisa de intervenção no ensino com o objetivo de desenvolver o conceito de fração em crianças de oito a dez anos. Justificando a importância do estudo, argumentam que fração é um tópico no qual as crianças apresentam muitas dificuldades decorrentes da complexidade inerente a esse conceito e da abordagem aplicada ao ensino desse conteúdo na escola. A fração é considerada de forma isolada, sem conexões com outros conceitos matemáticos e dissociada de situações extraescolares; seu ensino adota quase que exclusivamente uma representação simbólica formal associada a situações que requerem resoluções algorítmicas. Existe, então, a necessidade de se explorar formas alternativas de ensino que considerem uma visão mais ampla de fração tanto em termos de representação como de significado. Participaram do estudo 57 crianças, divididas em três grupos: Grupo Experimental (GE), com 19 alunos de $3^{a}$ série que não haviam recebido qualquer instrução sobre fração no contexto escolar; Grupo de Controle (GC), com 20 alunos de $3^{a}$ série que também não haviam recebido instrução sobre fração; e um Grupo de Referência (GR), com 18 alunos de $4^{\mathrm{a}}$ série que já haviam tido instrução formal sobre fração. A intervenção no GE consistiu em dez sessões, duas por semana, no horário regular de aulas, com uma dinâmica baseada na resolução de problemas de fração em pequenos grupos ou em pares, envolvendo problemas verbais, jogos e situações baseadas em atividades extraescolares. Foram aplicados pré e pós-teste em todos os grupos. Os dados foram analisados estatisticamente, e os resultados revelaram que a intervenção foi capaz de proporcionar ao GE uma compreensão mais apropriada sobre frações, especialmente na sua forma simbólica de representação, inclusive comparando o GE com o GR, que havia trabalhado frações e continuou tendo aulas tradicionais na $4^{\text {a }}$ série durante a pesquisa.

O artigo de Carvalho Junior (2010) teve por objetivo apresentar a Teoria dos Campos Conceituais de Gérard Vergnaud como um referencial teórico para o planejamento e para a análise de atividades de intervenção didática em aulas de Física. A teoria é descrita, e, a partir dessa descrição, são discutidas implicações para o ensino e é proposta uma metodologia cujo objetivo principal é a redução dos níveis de reprovação nas disciplinas de 
Física Aplicada e Mecânica Aplicada do Instituto Federal de Educação, Ciência e Tecnologia de Minas Gerais (IFMG) - Campus Congonhas. Essa metodologia estabelece uma abordagem conceitual privilegiando a discussão dos conceitos-chave do conteúdo dessas disciplinas, pois, no marco da teoria de Vergnaud, a conceitualização é o núcleo do desenvolvimento cognitivo. Além de conceitos, a abordagem também privilegia situações-problema que façam sentido para os alunos, pois são elas que constituem o referente dos conceitos. Outros aspectos importantes da metodologia em questão são a participação ativa do aluno e a correção de cada atividade pelo professor, que a devolve ao aluno com comentários sobre os acertos e erros cometidos. O início de cada aula é destinado a comentários sobre os modelos demonstrados pelos alunos. Não foram apresentados resultados, porque a intenção do trabalho era a de propor a teoria de Vergnaud como um referencial promissor para pesquisas em Ensino de Ciências em que se deseje enfocar o sujeito-em-ato, a interação-sujeito. Contudo, para o autor, os resultados preliminares de seu estudo são animadores.

Dias e Silva (2010) propõem a argumentação em aulas de Ciências como uma alternativa ao uso das Tecnologias de Informação e Comunicação (TICs) em cenários comuns à escola pública brasileira. No entanto, não se trata de substituir o uso das TICs pela argumentação, nem de dizer que elas não têm potencial para o Ensino de Ciências. O propósito é o de criticar declarações irrefletidas sobre o uso das TICs, particularmente no Ensino de Física, como se seu uso sem avaliação crítica fosse resolver as dificuldades do Ensino de Física decorrentes de uma abordagem tradicional, mecanicista, memorística. E também o de defender a argumentação, o diálogo argumentativo, como um recurso fundamental para o Ensino de Física. Embora seja o recurso mais antigo na história do ensino, é negligenciado na prática, pois esse ensino é usualmente monológico, centrado no professor. Os autores criticam a supervalorização das TICs na educação, deixando subjacente que são indispensáveis no ensino, e dão como contra exemplo o uso de slides PowerPoint, que pode minimizar ainda mais a intervenção dos estudantes, que se limitam a assistir as imagens, e o papel do professor é análogo ao de um guia que apresenta quadros em um museu. Reiteram, no entanto, que sua posição não é a de negar as TICs, mas sim a de defender a importância da argumentação no Ensino de Ciências.

O trabalho de Vilela e Dorta (2010) se ocupa do desenvolvimento do raciocínio lógico, um importante objetivo do Ensino de Matemática em todos os níveis, dentro de uma compreensão de desenvolvimento integral do estudante; mais precisamente, o trabalho aborda a lógica formal, a filosofia da lógica e a educação matemática. Nessa abordagem, os princípios da lógica clássica - princípio da identidade, princípio da não-contradição e princípio do terceiro excluído - são discutidos tomando como referente a obra Alice no país das maravilhas, de Charles L. Dogson, que a publicou sob o pseudônimo de Lewis Carroll. O autor foi professor de Matemática em Oxford, e nessa obra acopla conceitos e princípios da lógica formal ao mundo de fantasia vivido por Alice. Ao longo do artigo, os autores destacam que o objetivo de desenvolver o raciocínio lógico da criança 
deve ser considerado no contexto de sua formação integral. Chamam também a atenção para o fato de que esse desenvolvimento não é uma construção natural: deve ser aprendido, especificamente, em situações escolares. Nesse sentido, conceitos de lógica podem ser estudados, por exemplo, no contexto de uma obra como Alice no país das maravilhas e apresentados através das aventuras, dos sonhos e das fantasias de Alice e de personagens que com ela conviveram.

O tópico frações é também abordado por Silva (2010) desde a perspectiva dos processos cognitivos envolvidos. Usando o referencial piagetiano e o método da entrevista clínica, o autor investigou modelos de significação elaborados por adolescentes e adultos a propósito de problemas envolvendo frações. Foram conduzidas entrevistas clínicas com 29 sujeitos que haviam completado com sucesso a série escolar na qual são ensinadas frações, tinham mais de 12 anos e participaram voluntariamente da pesquisa. Inicialmente, pediu-se ao sujeito entrevistado que resolvesse o cálculo $1 / 2+1 / 3$ em uma folha de papel e fosse comentando como estava procedendo e pensando no desenrolar da solução. Em seguida, utilizando-se blocos de encaixe, com peças agrupadas duas a duas ou três a três, e cores distintas, perguntava-se ao sujeito se era possível construir duas torres de mesma altura utilizando em uma blocos de uma cor e em outra blocos de outra cor, sempre explorando o pensamento do sujeito ao explicar sua resposta, a solução encontrada. Uma situação um pouco mais complexa era proposta em uma segunda etapa. Os resultados evidenciam que apenas pequena parcela dos entrevistados foi capaz de elaborar uma explicação completa para um problema envolvendo cálculo com frações; os demais apresentaram explicações parciais ou incorretas, baseadas na percepção e na incompreensão da relação parte/todo. Na introdução de seu trabalho, os autores consideram que as frações são, em geral, um dos conteúdos mais difíceis da matemática escolar. Na conclusão, destacam que, se por um lado as operações lógico-matemáticas possuem uma lógica operatória, bastante estudada por Piaget, por outro existe também uma lógica de significações própria dos modelos que o sujeito constrói para interpretar a realidade, e esta deve ser considerada no ensino.

O Ensino de Estatística é o objeto do artigo de Pagan e Magina (2011). As autoras iniciam seu artigo destacando a importância que os gráficos estatísticos e as tabelas assumiram nas últimas décadas, nas mais variadas áreas de conhecimento. A partir daí decidiram investigar como se dá o Ensino de Estatística na educação básica, pois esse conteúdo é importante para a formação do cidadão, e a escola é, por excelência, o lugar para a aprendizagem de tal conteúdo. Como referencial teórico, usaram principalmente a Teoria de Registros de Representação Semiótica de Raymond Duval. Na pesquisa compararam os ganhos de aprendizagem entre três grupos de alunos de ensino médio que tiveram contato com conceitos elementares de Estatística (construção de gráficos e tabelas e leitura e interpretação de dados) em aulas de Geografia (Grupo GG), de Matemática (Grupo GM) e em aulas aplicadas de forma interdisciplinar (Grupo GI). Cada grupo tinha 35 alunos, e os conteúdos de Estatística 
foram previamente acertados entre os três professores, bem como o número de aulas (seis encontros de duas horas/aula cada um, em seis semanas). Foram aplicados pré e pós-testes idênticos nos três grupos e também idênticos entre si, isto é, o pré e o pós-testes foram iguais, menos na ordem das questões. Os dados obtidos foram analisados estatisticamente, e os resultados indicam que não houve diferença estatisticamente significativa entre os três grupos no pré-teste, porém, no pós-teste, o grupo GI apresentou desempenho estatisticamente superior aos outros dois grupos. Esse resultado indica que o Ensino da Estatística pautado nos moldes da interdisciplinaridade se mostrou mais eficaz do que o ensino dos mesmos conceitos no âmbito de uma disciplina específica. Esta foi, segundo as autoras, a principal conclusão da pesquisa.

Um estudo sobre ruptura e efeitos do contrato didático em uma aula de resolução de problemas algébricos no ensino fundamental foi conduzido e relatado por Araújo, Lima e Santos (2011). Tal estudo foi feito à luz da Didática (francesa) da Matemática, particularmente o Triângulo Didático proposto por Guy Brousseau, cujos vértices são o professor, o aluno e o saber. A relação entre professor e aluno com vista à apropriação do saber tem na sua base determinadas regras que determinam as responsabilidades de ambos na relação didática; tais regras constituem o contrato didático. No artigo, os autores aprofundam bem a noção de contrato didático e seus principais efeitos e, depois, descrevem uma pesquisa na qual analisaram os efeitos do contrato didático envolvendo um professor de Matemática e seus respectivos alunos (uma turma de $8^{\circ}$ ano de uma escola privada) na resolução de problemas algébricos a partir das interações discursivas em uma aula. Nas considerações finais, os autores relatam que identificavam ruptura do contrato didático na medida em que o professor propunha um problema matemático que feria uma lógica esperada pelos alunos (por exemplo, o resultado de um dos problemas era que uma pessoa tinha 2,5 sobrinhos). Mas observaram que o professor também se inquietava ao perceber que o problema por ele proposto era o desencadeador da ruptura do contrato. Contudo, os autores questionam a estabilidade plena do contrato, pois eliminaria a problematização, e argumentam em favor de desestabilizações e rupturas que permitem ao aluno pensar sobre o problema, com posterior retomada da estabilidade. Nesse contexto, a superação da ruptura e a retomada da estabilidade seriam indicadores de que o aluno aprendeu algo novo, e a relação com o saber do aluno e do professor já não é mais tão assimétrica.

Na próxima seção é apresentada, tentativamente, uma visão geral do conjunto de artigos até aqui sintetizados.

\section{Visão geral}

Considerando o conjunto dos 14 artigos, observa-se que a maioria (oito deles) é sobre Ensino de Matemática; depois vêm Ensino de Física, com três artigos, Ensino de Ciências, com dois, e Ensino de Biologia, com 
um. Nenhum artigo sobre Ensino de Química foi publicado na Rbep no período analisado.

Nos artigos sobre Ensino de Matemática, o conteúdo frações foi destacado como um dos mais difíceis da matemática escolar. O desenvolvimento do raciocínio lógico, a importância dos conceitos estatísticos, o aproveitamento do erro e o contrato didático foram também objeto dos artigos em Ensino de Matemática. Nos de Ensino de Física, um destacou a importância da argumentação, um teve um enfoque histórico e o terceiro propôs uma abordagem piagetiana para o planejamento do ensino. Os de Ensino de Ciências trataram do lúdico no processo ensino-aprendizagem e do potencial da análise de cadernos dos alunos. O único trabalho sobre Ensino de Biologia enfocou a epistemologia da Biologia, comparando-a com as da Matemática e da Física.

No que se refere à fundamentação teórica, o principal referencial foi a teoria de Piaget: praticamente a metade dos artigos usou Piaget como referência explícita. Um deles baseou-se explicitamente na teoria de Duval (representações semióticas) e outro, na de Brousseau (triângulo didático, contrato didático); os demais não apresentaram claramente um referencial teórico, embora tenham feito menção a certos teóricos e a trabalhos existentes na literatura.

Quanto à natureza dos trabalhos avaliados, metade deles, ou seja, sete, foram do tipo teórico/reflexivo, quatro, do tipo pesquisa qualitativa e três, na linha quantitativa.

Em relação ao nível de ensino abordado nos artigos, houve certo equilíbrio entre ensino fundamental e ensino médio, embora nos de Matemática predominasse o ensino fundamental. Nenhum trabalho tratou de Ensino de Ciências ou de Matemática em nível superior.

Finalmente, um aspecto presente em praticamente todos os artigos analisados foi a crítica ao ensino tradicional - expositivo, monológico, repetitivo, memorístico, extremamente apoiado no livro didático predominante na escola.

A partir daqui são feitos comentários pessoais sobre o Ensino de Ciências e de Matemática a partir das resenhas feitas, da visão geral apresentada e da experiência do autor.

\section{Aprendizagem mecânica}

Como foi dito, em praticamente todos os artigos há comentários ou menções críticas ao ensino tradicional, comportamentalista, treinador para provas, predominante no Ensino de Ciências e de Matemática (e de outras disciplinas) na escola brasileira (e de muitos outros países).

O modelo clássico de ensino, consagrado, aceito sem questionamento por professores, alunos e pais, pela sociedade em geral, é aquele no qual o professor ensina, básica e fundamentalmente, falando, dizendo aos estudantes aquilo que se supõe que devem saber. Esse modelo é o que Finkel (2008, p. 44) descreve como Dar aula narrando, ou seja, é o modelo 
da narrativa ao qual ele contrapõe o modelo de Dar aula com a boca fechada (p. 45), estimulando buscas de modelos alternativos.

No modelo da narrativa, muitas vezes baseado em um único livro de texto, o professor escreve (uma forma de narrar) no quadro o que os alunos devem copiar em seus cadernos, estudar (memorizar) e depois reproduzir nas avaliações. Às vezes o professor escreve no quadro partes do próprio livro de texto, mas ainda assim os alunos copiam para estudar mais tarde, em geral na noite anterior às provas, para não esquecer. $\mathrm{O}$ modelo continua igual se o quadro de giz for substituído por apresentações PowerPoint e o professor passar os arquivos eletrônicos a seus alunos para que os gravem em seus pen drives.

Esse modelo deveria ser questionado, porque transmitir o conhecimento a partir da cabeça do professor até o caderno do aluno, a fim de que este o transfira até sua cabeça para depois reproduzi-lo nas provas, é um objetivo inadequado para a educação e, muito mais ainda, para uma aprendizagem significativa crítica.

É um modelo orientado para a aprendizagem de informações específicas de curto prazo, para respostas corretas sem necessidade de entendê-las, explicá-las. É um modelo comportamentalista (as respostas corretas são os comportamentos esperados). Pouco sobra dessa aprendizagem depois de algum tempo.

Muitas vezes os professores são considerados excelentes expositores, fazem magníficas exposições orais, encantam os alunos explicando clara e detalhadamente determinados conteúdos. Esses alunos anotam tudo que podem e saem da aula com a boa sensação de que entenderam o assunto. Se esse assunto for pedido nas provas da mesma maneira que o professor ensinou, provavelmente se sairão muito bem.

No entanto, se as questões das avaliações implicarem a aplicação desses conteúdos a situações não trabalhadas em aula, é provável que não se saiam bem. Nesse caso, é comum os alunos queixarem-se de que "a matéria não foi dada", que houve quebra do contrato didático implícito no modelo da narrativa.

Na ótica da educação bancária de Freire (1988), dir-se-ia que a matéria não foi depositada na cabeça dos alunos. Na educação bancária, o ensino é o ato de depositar, transferir, transmitir valores e conhecimentos ao aluno. Nessa concepção, estudar é memorizar conteúdos mecanicamente, sem significados. O que se espera do educando é a memorização dos conteúdos nele depositados. A compreensão e a significação não são requisitos, a memorização sim (Freire, 1988). Em tal concepção, o educador é quem pergunta e cobra do educando respostas memorizadas.

Nos dias de hoje fala-se em ensino centrado no aluno, no professor como mediador e em aprender a aprender. Mas é só discurso; na prática continua plenamente vigente o modelo da narrativa, ou bancário, que estimula, promove, exalta aquela aprendizagem que Ausubel (2000) cunhou como aprendizagem mecânica (rote learning).

Aprendizagem mecânica é aquela em que há um armazenamento literal, arbitrário, sem significado, de informações na estrutura cognitiva 
do aluno: não requer compreensão; resulta em aplicação mecânica a situações conhecidas.

Em contraposição, a aprendizagem significativa implica incorporação substantiva, não arbitrária, com significado, de corpos organizados de conhecimento à estrutura cognitiva; implica compreensão, captação de significados, capacidade de explicar, descrever, transferir, enfrentar situações novas.

Aprendizagem mecânica e aprendizagem significativa não constituem dicotomia, estão ao longo de um contínuo. As descrições acima se referem aos extremos desse contínuo. Normalmente, o processo ensinoaprendizagem se desenvolve em uma região intermediária desse contínuo, em uma zona cinza, em uma região de progressividade das aprendizagens. No entanto, o modelo clássico, behaviorista, da narrativa estimula largamente a aprendizagem mecânica, não a significativa.

Mas, como foi dito no início desta seção, este é o modelo consagrado, preferido, aquele que a sociedade quer. Não se trata, então, de culpar os professores. Estamos em uma sociedade em que a educação, a escola, está altamente dirigida para a testagem. Como disse a diretora da Faculdade de Educação de Stanford, Deborah Stipek, em um editorial da revista Science (2011), Educação não é uma corrida (Educação is not a race), mas, na prática, a escola atua como se assim fosse, treinando o aluno para os vestibulares e para os testes nacionais e internacionais - as melhores escolas são aquelas que têm mais alunos aprovados nos testes. É uma educação, ou melhor dito, um treinamento para a testagem, uma preparação para a corrida dos testes.

Subjacente a essa preparação para a testagem está a aprendizagem mecânica, tão criticada pelos autores dos estudos em Ensino de Ciências e de Matemática, objeto do presente texto.

\section{Referenciais teóricos}

Sem pensar em considerações estatísticas, pois foram analisados apenas 14 estudos, chama a atenção a predominância do referencial piagetiano. Claro que a contribuição de Piaget para o Ensino de Ciências e de Matemática é muito importante. A de Vygotsky também. A didática francesa igualmente. Mas não seria o caso de buscar outros referenciais? A teoria dos campos conceituais de Vergnaud, por exemplo, foi usada como referente teórico básico em um dos trabalhos (mas, ainda assim, em uma visão piagetiana) e mencionada em dois outros. A teoria da aprendizagem significativa não foi usada como fundamentação teórica em nenhum trabalho.

A psicologia cognitiva de hoje é a da mente computacional representacional, mas também não foi tomada como referente teórico em nenhum dos estudos. Estamos no século 21, mas os referenciais dominantes nas pesquisas em Ensino de Ciências e de Matemática parecem ser os de um século atrás. Algo para refletir. 


\section{Pesquisa básica e pesquisa aplicada}

Dos trabalhos abordados, metade poderia ser caracterizada como teóricos/reflexivos e metade, como pesquisa. Certamente, a teorização e a reflexão são relevantes, até mesmo imprescindíveis, no Ensino de Ciências e de Matemática, mas talvez estejamos necessitando de mais pesquisas no momento atual, principalmente pesquisas aplicadas, feitas na sala de aula, envolvendo professores.

A pesquisa em Ensino de Ciências e de Matemática está consolidada em âmbito nacional e internacional. Existem revistas de alto nível, programas de pós-graduação, congressos, grupos de pesquisa, associações, ou seja, tudo o que caracteriza uma área consolidada. Mas grande parte dessa pesquisa pode ser classificada como pesquisa básica, cujos produtos, os "papers", são gerados para serem compartilhados entre os próprios pesquisadores. Seu impacto no ensino é muito pequeno; os artigos publicados não chegam aos professores, não influenciam as práticas docentes.

Provavelmente, a pesquisa aplicada, aquela voltada explicitamente para a solução de problemas do Ensino de Ciências e de Matemática, tenha mais contribuições no momento atual do que a pesquisa básica. Contudo, a pesquisa básica é muito mais valorizada no contexto acadêmico. É também algo para pensar.

\section{A atualização curricular e a tecnologia}

Aspectos não abordados nos artigos considerados, mas de grande importância para o Ensino de Ciências e de Matemática, são o do currículo desatualizado e o da não incorporação das TICs nas práticas docentes.

No caso da Física, por exemplo, o currículo está altamente desatualizado em termos de conteúdos. A Física ensinada nas escolas vai até o século 19. Os tópicos ensinados atualmente são os mesmos (porém com menos aulas) de 50 anos atrás, ou mais. Os alunos de hoje vivem em um mundo de tecnologias envolvendo Física de Plasmas, Física Quântica, Física de Partículas, etc., mas, nas aulas de Física, o que devem aprender (mecanicamente) é o movimento retilíneo uniforme, o plano inclinado, as alavancas...

Se aceitarmos a premissa de Vergnaud (1990) de que são as situações que dão sentido aos conceitos, entenderemos facilmente porque os alunos geralmente não gostam de Física e porque a encaram apenas como fórmulas a serem decoradas e aplicadas à resolução de problemas conhecidos.

No ensino da Biologia e da Química a situação deve ser similar. O que se ensina na escola deve estar longe dos conhecimentos biológicos e químicos atuais. No ensino da Matemática talvez a situação não seja muito diferente.

Em relação às TICs, o artigo de Dias e Silva (2010) chama a atenção para a sua supervalorização por alguns autores e pela sua utilização 
acrítica, como se fosse a solução para o Ensino de Ciências, particularmente de Física. Suas críticas são pertinentes, mas é inegável que vivemos em uma sociedade onde as TICs estão onipresentes, exceto na escola. Inclusive, quando existem laboratórios de informática, ou até mesmo quando existe um computador por aluno, o uso das TICs, da informática educativa, da simulação computacional, da modelagem computacional, da aquisição automática de dados, de laboratórios virtuais é mínimo ou nenhum.

\section{Considerações finais}

Grande parte deste trabalho foi dedicada a breves resenhas de estudos na área de Ensino de Ciências e de Matemática publicados na Rbep no período de 1998 a 2011. De modo geral, são bons trabalhos que permitem inferir que o Brasil vai bem nessa área. Artigos publicados aproximadamente no mesmo período em revistas como Ciência e Educação, Investigações em Ensino de Ciências, Revista Brasileira de Pesquisa em Educação em Ciências, Bolema: Boletim de Educação Matemática confirmam essa inferência. De fato, em termos de publicações estamos muito bem.

Outro ponto importante a considerar é a criação, em 2000, da Área de Ensino de Ciências e de Matemática, a Área 46, na Capes. No começo eram uns poucos mestrados e doutorados. Hoje essa área é simplesmente de Ensino, mas como resultado de sua criação temos dezenas de mestrados acadêmicos, dezenas de mestrados profissionais e muitos doutorados em Ensino de Ciências e de Matemática espalhados pelo Brasil. Na pós-graduação strictu sensu nessa área estamos muito à frente dos demais países latino-americanos.

Então, como se explica que o Ensino de Ciências e de Matemática em nossas escolas seja tão fraco?

Bem, seria ingenuidade pensar que esse ensino fosse depender somente de boas publicações, boas pesquisas e bons cursos de pósgraduação. Isso é importante, mas o ensino de uma área de conhecimentos em um país depende crucialmente das políticas educacionais. No Brasil, os salários dos professores são muito baixos, os cursos de formação de professores são bastante fracos em termos de conteúdos (por exemplo, como ensinar Física Moderna e Contemporânea no ensino médio, se os professores não têm formação nesse conteúdo?) e o número de aulas em alguns casos é muito pequeno, quase nada (em Física, por exemplo, há escolas em que a carga horária é de 1h/semana).

Outro fator que distorce completamente o Ensino de Ciências e de Matemática no Brasil é a preocupação total com a testagem; educação científica e educação matemática não é isso - educação não é corrida (Stipek, 2011). A testagem mede, não avalia. A preparação para a testagem treina, não educa. O que esperamos do Ensino de Ciências e de Matemática? Alunos treinados para dar respostas corretas ou cidadãos educados cientificamente e matematicamente? 


\section{Referências bibliográficas}

ARAÚJO, L. F.; LIMA, A. P. A. B.; SANTOS, M. C. Ruptura e efeitos do contrato didático numa aula de resolução de problemas algébricos. Revista Brasileira de Estudos Pedagógicos, Brasília, v. 92, n. 232, p. 739-756, set./dez. 2011.

AUSUBEL, D. P. The acquisition and retention of knowledge: a cognitive view. Dordrecht: Kluwer Academic Publishers, 2000.

BELLINI, M. Epistemologia da Biologia: para se pensar a iniciação ao ensino das Ciências Biológicas. Revista Brasileira de Estudos Pedagógicos, Brasília, v. 88, n. 218, p. 30-47, jan./abr. 2007.

BERTI, N. M.; ROSSO, A. J.; BURAK, D. Compreensão do erro em Matemática e significado a ele atribuído pelos alunos da $5^{\mathrm{a}}$ série. Revista Brasileira de Estudos Pedagógicos, Brasília, v. 89, n. 223, p. 553-575, set./dez. 2008.

CARVALHO JR., G. D. Uma abordagem piagetiana para o planejamento do ensino de Física em cursos técnicos. Revista Brasileira de Estudos Pedagógicos, Brasília, v. 91, n. 227, p. 105-121, jan./abr. 2010.

CAZORLA, I. M.; UTSUMI, M. C.; SANTANA, E. R. S.; VITA, A. C. Relação entre o domínio afetivo e o desempenho em Matemática de estudantes das séries iniciais do ensino fundamental. Revista Brasileira de Estudos Pedagógicos, Brasília, v. 89, n. 221, p. 145-161, jan./abr. 2008.

DIAS, A. S.; SILVA, A. P. B. A argumentação em aulas de Ciências como uma alternativa ao uso das novas tecnologias de informação e comunicação em cenários comuns à escola pública brasileira. Revista Brasileira de Estudos Pedagógicos, Brasília, v. 91, n. 229, p. 622-633, set./dez. 2010.

DIOGO, R. C.; GOBARA, S. T. Educação e ensino de Ciências Naturais/ Física no Brasil: do Brasil Colônia à Era Vargas. Revista Brasileira de Estudos Pedagógicos, Brasília, v. 89, n. 222, p. 365-383, maio/ago. 2008.

FINKEL, D. Dar clase con la boca cerrada. Valencia, Espanha: Publicaciones de la Universitat Valencia, 2008.

FREIRE, P. Pedagogia do oprimido. 18. ed. São Paulo: Paz e Terra, 1988.

MAGINA, S.; BEZERRA, F. B.; SPINILLO, A. Como desenvolver a compreensão da criança sobre fração? Uma experiência de ensino. Revista Brasileira de Estudos Pedagógicos, Brasília, v. 90, n. 225, p. 411-432, maio/ago. 2009. 
NASCIMENTO, R. B. A Geometria via ambiente Logo. Revista Brasileira de Estudos Pedagógicos, Brasília, v. 81, n. 197, p. 89-108, jan./abr. 2000.

PAGAN, A.; MAGINA, S. O ensino de Estatística na educação básica com foco na interdisciplinaridade: um estudo comparativo: Revista Brasileira de Estudos Pedagógicos, Brasília, v. 92, n. 232, p. 723-738, set./dez. 2011.

SILVA, A. M. T. B; METTRAU, M. B; BARRETO, M. S. L. O lúdico no processo ensino-aprendizagem das Ciências. Revista Brasileira de Estudos Pedagógicos, Brasília, v. 88, n. 220, p. 445-458, set./dez. 2007.

SILVA, J. A. Processos cognitivos envolvidos no cálculo com frações. Revista Brasileira de Estudos Pedagógicos, Brasília, v. 91, n. 229, p. 652-678, set./dez. 2010.

SIQUEIRA, L. S.; ARAÚJO-JORGE, T. C. Práticas docentes e discentes em Cadernos de Ciências: desenvolvimento metodológico para percepção dos diferentes registros do cotidiano escolar. Revista Brasileira de Estudos Pedagógicos, Brasília, v. 89, n. 221, p. 47-71, jan./abr. 2008.

STIPEK, D. Education is not a race. Science, Washington, DC, v. 332, p. $1481,2011$.

VERGNAUD, G. La théorie des champs conceptuels. Recherches en Didactique des Mathématiques, Grenoble, France, v. 10, n. 23, p. 133-170, 1990.

VILELA, D. S.; DORTA, D. O que é "desenvolver raciocínio lógico"? Considerações a partir do livro Alice no país das maravilhas. Revista Brasileira de Estudos Pedagógicos, Brasília, v. 91, n. 229, p. 634-651, set./dez. 2010.

Marco Antonio Moreira, Ph.D. em Ensino de Ciências pela Cornell University, é professor do Instituto de Física da Universidade Federal do Rio Grande do Sul (UFRGS) e pesquisador 1A do Conselho Nacional de Desenvolvimento Científico e Tecnológico (CNPq), na Área de Educação. Coordenou a Área de Ensino de Ciências e de Matemática na Coordenação de Aperfeiçoamento de Pessoal de Nível Superior (Capes), de 2000 a 2007. Além do Ensino da Física, dedica-se a Teorias de Aprendizagem e à Epistemologia da Ciência.

moreira@if.ufrgs.br 